\title{
Update to the Hong Kong Epilepsy Guideline: evidence-based recommendations for clinical management of women with epilepsy throughout the reproductive cycle
}

Richard SK Chang, Kate HK Lui, William Ip, Eric Yeung, Ada WY Yung, Howan Leung *, Eva LW Fung, Ben BH Fung, Eric LY Chan, TL Poon, HT Wong, Deyond Siu, Kevin Cheng, Cannon XL Zhu, Gardian CY Fong, Jonathan Chu, Colin HT Lui, Maggie Yau

\section{A B S T R A C T}

Since the publication of the Hong Kong Epilepsy Guideline in 2009, there has been significant progress in antiepileptic drug development. New antiepileptic drugs have emerged, and data about their uses have been published. Women require special attention in epilepsy care. Drug teratogenicity, pregnancy, breastfeeding, contraception, reproduction technology, menopause, and catamenial epilepsy are major topics. Antiepileptic drugs should be chosen individually for patients who are pregnant or may become pregnant with consideration of their teratogenicity and seizure control properties. Folate is commonly prescribed for women of childbearing age who are taking antiepileptic drugs. Spontaneous vaginal delivery and breastfeeding are not contra-indicated in most cases but need to be considered individually based on the patient's medical condition and wishes. Serum drug level monitoring of certain antiepileptic drugs during pregnancy and puerperium can guide dosage adjustment. For catamenial epilepsy, intermittent benzodiazepines such as clobazam during the susceptible phase of the menstrual cycle could be a treatment option.
Hong Kong Med J 2020;26:421-31

https://doi.org/10.12809/hkmj198367

${ }^{1}$ RSK Chang, FHKCP, FHKAM (Medicine)

${ }^{2}$ KHK Lui, FHKCP, FHKAM (Medicine)

${ }^{2}$ W Ip, MRCP (UK)

${ }^{3}$ E Yeung, FHKCP, FHKAM (Medicine)

${ }^{4}$ AWY Yung, FHKCP, FHKAM (Paediatrics)

${ }^{5}$ H Leung *, FHKCP, FHKAM (Medicine)

${ }^{6}$ ELW Fung, FHKCPaed, FHKAM (Paediatrics)

${ }^{4}$ BBH Fung, FHKCP, FHKAM (Medicine)

${ }^{7}$ ELY Chan, FHKCP, FHKAM (Medicine)

${ }^{8}$ TL Poon, FCSHK, FHKAM (Surgery)

${ }^{9}$ HT Wong, FCSHK, FHKAM (Surgery)

${ }^{10} \mathrm{D}$ Siu, FHKCR, FHKAM (Radiology)

${ }^{11} \mathrm{~K}$ Cheng, FCSHK, FHKAM (Surgery)

${ }^{12}$ CXL Zhu, FRCS, FHKAM (Surgery)

${ }^{4}$ GCY Fong, FHKCP, FHKAM (Medicine)

$1 \mathrm{~J}$ Chu, FHKCP, FHKAM (Medicine)

${ }^{2}$ CHT Lui, FHKCP, FHKAM (Medicine)

${ }^{6}$ M Yau, FHKCP, FHKAM (Paediatrics)

Department of Medicine, Queen Mary Hospital, Hong Kong

2 Department of Medicine, Tseung Kwan O Hospital, Hong Kong

Department of Medicine, Pamela Youde Nethersole Eastern Hospital,

Hong Kong

${ }^{4}$ Private Practice, Hong Kong

${ }^{5}$ Department of Medicine and Therapeutics, Prince of Wales Hospital, Hong Kong

${ }^{6}$ Department of Paediatrics, Prince of Wales Hospital, Hong Kong

7 Department of Medicine and Geriatrics, Tuen Mun Hospital, Hong Kong

${ }^{8}$ Department of Neurosurgery, Queen Elizabeth Hospital, Hong Kong

${ }^{9}$ Department of Neurosurgery, Kwong Wah Hospital, Hong Kong

${ }^{10}$ Department of Radiology, Kwong Wah Hospital, Hong Kong

${ }^{11}$ Department of Neurosurgery, Queen Mary Hospital, Hong Kong

${ }^{12}$ Department of Surgery, Prince of Wales Hospital, Hong Kong

* Corresponding author: howanleung@cuhk.edu.hk

\section{Introduction}

Women need special attention in epilepsy care. They face various challenges related to their reproductive cycles, including pregnancy, breastfeeding, contraception, menopause, and catamenial epilepsy. Antiepileptic drug (AED) options have increased exponentially in recent decades. New data on epilepsy management have emerged since the 2009 publication of the Hong Kong Epilepsy Guideline by the Hong Kong Epilepsy Society. ${ }^{1}$ This article aims to update the Society's guideline with a focus on epilepsy management in women. This project received no specific grant from any funding agency in the public, commercial, or not-for-profit sectors.

\section{Preconception counselling and teratogenicity of antiepileptic drugs}

Women with epilepsy, preferably with their partner or parents if appropriate, should receive counselling on contraception, conception, pregnancy, breastfeeding, and childcare. Preconception counselling is especially important for women who 


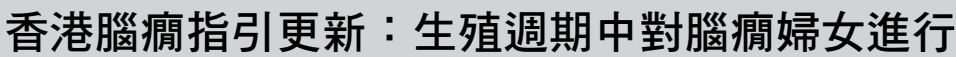 臨床管理的循證醫學建議}

張錫坤、呂凱琪、葉俊德、楊思偉、楊穎欣、梁浩雲、 馮麗華、馮斌熙、陳樂耀、潘德立、黃海東、蕭容媛、

鄭璟暉、朱獻倫、方頌恩、朱炎培、呂曉東、邱露儀

自2009年發佈香港腦痭指引以來, 抗腦痌藥的開發取得重大進展。新 的抗腦痌藥及其用途的數據已被發表。婦女在腦疡治療中需要特別留 意。藥物致畸性、懷孕、母乳喂養、避孕、生殖技術、更年期和月經 期腦疡是重要主題。考慮到其致畸性和腦疡發作控制特性, 應為懷孕

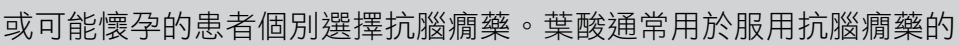
育齡婦女。大多數情況下, 自發陰道分娩和母乳喂養不是禁忌的, 但 須根據患者的醫療狀況和意願作個別考慮。在妊娠和產裖期監測某些 抗腦疡藥的血清藥物水平可以指引劑量調整。對於月經性腦癇, 在月 經週期的敏感階段間歇使用苯二氮卓類藥物（如氯巴沙姆）可作其中 一種治療選擇。 with higher dosages of AEDs. ${ }^{12}$ Antenatal screening including fetal ultrasound scan can help to detect major fetal malformations. ${ }^{2}$ However, prenatal screening has limitations in terms of malformation detection and cannot provide information about neurodevelopmental complications. ${ }^{15}$

The North American Antiepileptic Drug Pregnancy Registry (NAAPR) reported that phenobarbital monotherapy was associated with an increased MCM rate of $6.5 \%$ (95\% confidence interval [CI], 2.1\%-14.5\%) compared with the background rate of $1.6 \%{ }^{16}$ The same registry later reported that the MCM risk associated with phenobarbital was $5.5 \%$ in a larger group of 199 pregnancies. ${ }^{17}$ The teratogenic effects of phenobarbital are probably related to dosage. Data from the European Registry of Antiepileptic Drugs and Pregnancy (EURAP) showed that phenobarbital had an MCM risk of 5.4\% (95\% CI, 2.51\%-10.04\%) in the offspring of women taking daily doses $<150 \mathrm{mg}$. The risk increased to $13.7 \%$ (95\% CI, $5.70 \%-26.26 \%)$ at daily doses of $150 \mathrm{mg}$ per day or above. Phenobarbital may also have deleterious effects on the cognition of offspring. ${ }^{12,18}$

A meta-analysis found that phenytoin had an MCM rate of $7.4 \%$ (95\% CI, 3.60\%-11.11\%). ${ }^{14}$ The go reasured the met outcones. They should uneventful pregnancies and deliveries. ${ }^{2}$

The risk of epilepsy in the offspring of women with epilepsy is highly dependent on the parents' epilepsy syndrome status. ${ }^{3}$ In general, the risk is slightly higher compared with that of the background population. In a large population-based study, the overall cumulative risk of epilepsy up to age 40 in individuals with epileptic parents was $4.5 \%$, which is about 3-fold higher than that of the general population. ${ }^{4}$ Referral to appropriate specialists such as geneticists is appropriate if genetic counselling is indicated.

Animal studies have shown that AEDs can decrease the level of serum folate, increasing the risk of fetal neural tube defects. ${ }^{5}$ Neonatal malformations have also been associated with low maternal serum folate levels in humans. ${ }^{6}$ All women with epilepsy of childbearing age may be offered folate supplements while on AEDs. ${ }^{7,8}$ Although there is no definite consensus about folate dosage, it is reasonable to prescribe oral folate $5 \mathrm{mg}$ daily to women with childbearing potential. ${ }^{1,2,9}$

Many AEDs have the ability to cross the placenta. ${ }^{7}$ Data have emerged on the potential risks of in-utero AED exposure to offspring. The risk of major congenital malformations (MCMs) such as hypospadias, congenital heart defects, club foot, cleft lip or palate, and spina bifida in children born to women with epilepsy treated with AEDs during pregnancy is 2 to 3 times higher than the $2 \%$ to $5 \%$ occurrence rate in the general population. . $^{10,11}$ Polytherapy probably has a higher risk of MCMs and future cognitive adverse drug effects compared with monotherapy. ${ }^{12-14}$ The risk of MCMs may increase
EURAP reported that the MCM rate associated with phenytoin was approximately $6.4 \%(95 \% \mathrm{CI}$, $2.8 \%-12.2 \%) .{ }^{19}$ The NAAPR reported that phenytoin was associated with a $2.9 \%$ risk of MCMs (compared with a background rate of $1.1 \%) .{ }^{17}$ The UK and Ireland Epilepsy and Pregnancy Register reported that the risk of MCMs associated with phenytoin was $3.7 \% .^{20-22}$ There is also evidence showing that in-utero phenytoin exposure is associated with an increased risk of impaired cognition. ${ }^{23-25}$

Valproate use during pregnancy may be associated with MCMs and long-term negative effects on the cognitive and neurological functions of offspring. Neural tube defects, facial clefts, and hypospadias may be related to in-utero valproate exposure..$^{13,26-29} \mathrm{~A}$ meta-analysis showed that the overall risk of MCMs associated with in-utero exposure to valproate was $10.73 \%$ (95\% CI, 8.16\%-13.29\%). ${ }^{14}$ The European Surveillance of Congenital Anomalies study found that valproate monotherapy was associated with significantly increased risks of six specific malformations, with the following odds ratios (ORs): spina bifida, 12.7 -fold increase $(95 \% \mathrm{CI}$, 7.7-20.7); atrial septal defect, 2.5-fold (1.4-4.4); cleft palate, 5.2-fold (2.8-9.9); hypospadias, 4.8-fold (2.9-8.1); polydactyly, 2.2-fold (1.0-4.5); and craniosynostosis, $\quad 6.8$-fold $\quad(1.8-18.8){ }^{30}$ Adverse effects in terms of mental and motor development have been shown to be associated with in-utero valproate exposure in children. ${ }^{31-35}$ In 2011, the US Food and Drug Administration (FDA) issued a warning about valproate use during pregnancy because interim results from the NEAD 
(Neurodevelopmental Effects of Antiepileptic Drugs) study and other epidemiological studies showed lower cognitive function in children with in-utero valproate exposure. ${ }^{31,36,37}$ The NEAD study was a prospective multicentre cohort study conducted in the US and UK. Interim cognitive assessment at age 3 years showed that children exposed to valproate had intelligence quotient (IQ) scores 9 points lower than those exposed to lamotrigine (95\% CI, 3.1-14.6; $\mathrm{P}=0.009), 7$ points lower than those exposed to phenytoin (95\% CI, 0.2-14.0; $\mathrm{P}=0.04$ ), and 6 points lower than those exposed to carbamazepine (95\% CI, 0.6-12.0; $\mathrm{P}=0.04)$. The association between valproate use and detrimental effects on IQ was dose-dependent. ${ }^{31}$ When 244 newborn children subsequently completed 6 years of follow-up, mean IQ at age 6 years was lower in children exposed to valproate $(97 ; 95 \% \mathrm{CI}, 94-101)$ than to carbamazepine (105; 95\% CI, 102-108; $\mathrm{P}=0.0015)$, lamotrigine (108; 95\% CI, 105-110; $\mathrm{P}=0.0003)$, or phenytoin (108; 95\% CI, 104-112; $\mathrm{P}=0.0006) .{ }^{32}$ Children exposed to valproate were inferior in terms of verbal and memory abilities to those exposed to the other AEDs and in terms of non-verbal and executive functions to those exposed to lamotrigine. High doses of valproate were negatively associated with IQ, verbal ability, non-verbal ability, memory, and executive function. ${ }^{32}$ Valproate use during pregnancy may also increase the risk of childhood autism in offspring (adjusted hazard ratio: $2.9 ; 95 \% \mathrm{CI}, 1.4-6.0) .^{38,39} \mathrm{In}$ 2013, the FDA strengthened its warning regarding valproate use: it suggested that valproate should only be used in epileptic pregnant women if other medications are ineffective or unacceptable, and it is contra-indicated for migraines during pregnancy. In women with epilepsy who are currently not pregnant but have the potential to become pregnant, valproate should not be considered as the first-line treatment, especially for focal epilepsies, unless there is no other alternative. For cases in which valproate is considered as an appropriate option, like certain idiopathic generalised epilepsies, the dose should be maintained at the lowest effective dose, preferably not exceeding 500 to $800 \mathrm{mg}$ per day. ${ }^{15} \mathrm{In}$ special circumstances, the use of valproate as initial treatment may be justifiable. For example, it could be used in epilepsies with high likelihood of remission and drug withdrawal before puberty or in patients with severe disabilities that make future pregnancy extremely unlikely. ${ }^{15}$ The American Academy of Neurology has recommended that valproate be avoided during the first trimester of pregnancy if possible. ${ }^{40}$ However, the use of valproate in women with epilepsy should be individualised with consideration of the dosage administered, seizure control, and potential effects on offspring. In certain cases, especially those of specific epilepsy syndromes such as juvenile myoclonic epilepsy and juvenile absence epilepsy, valproate may be the most suitable choice after balancing its seizure control properties with the potential adverse effects on both the patient and her offspring. Valproate may also be used when clear communication with the patient about the risk-benefit ratio has been undertaken.

Although the number of women with childbearing potential who take valproate is decreasing, there are persistent concerns about inadequate information provided to valproate users about its possible adverse effects on their offspring. Authorities from various countries or regions, such as the UK and the European Union, have adopted specific risk minimisation measures surrounding valproate usage among women with epilepsy. Examples include the provision of information leaflets highlighting the potential teratogenic and neurodevelopmental impacts of valproate exposure in utero, pregnancy tests before valproate prescription, a risk acknowledgement form filled upon valproate initiation and renewed annually by healthcare professionals, and alert cards provided to women with epilepsy with childbearing potential. These could serve as references to healthcare providers in different clinical settings. Direct adoption of these measures may not be feasible in some local situations. Certain practices may be advisable to enhance communication between prescribers and potential childbearing female valproate users. The indications and potential adverse effects of valproate could be communicated to patients in different formats, such as on paper or electronically. The plan of valproate therapy should be reviewed with women with epilepsy with pregnancy potential when clinically indicated, but not necessarily on a yearly basis. Other medical professionals (eg, nurses or pharmacists) could take a role in AED counselling, including advising patients regarding their potential adverse effects. Materials could be provided to patients regarding the drugs' potential implications on pregnancy and fetal outcomes. These could be in the form of leaflets, warning messages, or QR codes on drug packaging. Good documentation of the communication between the clinician and patient, preferably including the family, cannot be overemphasised.

The NAAPR reported that carbamazepine monotherapy during pregnancy had a $2.9 \%$ overall risk of MCMs. ${ }^{17}$ The European Surveillance of Congenital Anomalies Database reported that the OR of spina bifida related to carbamazepine monotherapy was 2.6 versus no AEDs. ${ }^{41}$ The EURAP has also demonstrated a dose-dependent effect of carbamazepine. Carbamazepine doses of $>400 \mathrm{mg}$ per day were associated with a significantly higher risk of MCMs (5.3\% for $\geq 400$ to $<1000 \mathrm{mg} ; 8.7 \%$ for $\geq 1000 \mathrm{mg}$ ) [Table $1^{17,19,21,42,43}$.

A 2008 meta-analysis showed that lamotrigine 
TABLE I. Risk of major congenital malformations in offspring of women on various monotherapies of antiepileptic drugs. Because the data are not from single studies, direct comparison is inappropriate

\begin{tabular}{|cc|}
\hline Monotherapy & $\begin{array}{c}\text { Rate of MCMs } \\
\text { (95\% confidence interval) }\end{array}$ \\
\hline Carbamazepine & \\
\hline$<400 \mathrm{mg}$ & $3.4 \%(1.11 \%-7.71 \%)^{\star}$ \\
$\quad \geq 400$ to $<1000 \mathrm{mg}$ & $5.3 \%(4.07 \%-6.89 \%)^{\star}$ \\
\hline$\geq 1000 \mathrm{mg}$ & $8.7 \%(5.24 \%-13.39 \%)^{\star}$ \\
\hline Lamotrigine & \\
\hline$<300 \mathrm{mg}$ & $2.0 \%(1.19 \%-3.24 \%)^{\star}$ \\
\hline$\geq 300 \mathrm{mg}$ & $4.5 \%(2.77 \%-6.87 \%)^{\star}$ \\
\hline Phenobarbital & \\
\hline$<150 \mathrm{mg}$ & $5.4 \%(2.51 \%-10.04 \%)^{\star}$ \\
\hline$\geq 150 \mathrm{mg}$ & $13.7 \%(5.70 \%-26.26 \%)^{\star}$ \\
\hline Valproate & \\
\hline$<700 \mathrm{mg}$ & $5.6 \%(3.60 \%-8.17 \%)^{\star}$ \\
\hline$\geq 700 \mathrm{to}<1500 \mathrm{mg}$ & $10.4 \%(7.83 \%-13.50 \%)^{\star}$ \\
\hline$\geq 1500 \mathrm{mg}$ & $24.2 \%(16.19 \%-33.89 \%)^{\star}$ \\
\hline Levetiracetam & $0.70 \%(0.19 \%-2.51 \%)^{21}$ \\
\hline Oxcarbazepine & $2.2 \%(0.6 \%-5.5 \%)^{17}$ \\
\hline Phenytoin & $6.4 \%(2.8 \%-12.2 \%)^{19}$ \\
\hline Pregabalin & $5.9 \%(2.4 \%-6.8 \%)^{19}$ \\
\hline Topiramate & \\
\hline Ab & \\
\hline
\end{tabular}

Abbreviation: $\mathrm{MCM}=$ major congenital malformation

* MCM(s) in offspring detected up to age I year ${ }^{42}$

monotherapy had an MCM risk of $2.91 \%$ (95\% CI, $2.00 \%-3.82 \%){ }^{14}$ The NAAPR has indicated that lamotrigine monotherapy carried a $1.9 \%$ risk of MCMs. ${ }^{44}$ The EURAP pregnancy registry data show a relatively low risk of malformations when using lamotrigine monotherapy at doses $<300 \mathrm{mg}$ per day as compared with other AEDs (Table 1). ${ }^{42}$ When used as polytherapy, the combination of lamotrigine and valproate may have a relatively higher risk of MCMs (9.1\%; OR=5.0; 95\% CI, 1.5\%-14\%) compared with combinations of lamotrigine and other AEDs (2.9\%; OR=1.5; 95\% CI, 0.7\%-3.0\%). ${ }^{44}$

The UK and Ireland Epilepsy and Pregnancy Register reported that levetiracetam monotherapy has a $0.70 \%$ risk of MCMs $(95 \% \mathrm{CI}, 0.1 \%-2.51 \%){ }^{21}$ The MCM risk of levetiracetam as polytherapy was relatively higher at $6.47 \%$ (95\% CI, $4.31 \%-9.60 \%$ ). The MCM rates of polytherapy including levetiracetam varied with different regimens: the combination of levetiracetam and lamotrigine had a risk of $1.77 \%$ (95\% CI, $0.49 \%-6.22 \%$ ) compared with 6.90\% (95\% CI, 1.91\%-21.96\%) for the combination of levetiracetam and valproate and $9.38 \%$ (95\% CI, $4.37 \%-18.98 \%$ ) for the combination of levetiracetam and carbamazepine.
The FDA issued a warning regarding an increased risk of oral cleft in children born to mothers taking topiramate based on data from the NAAPR and the UK Epilepsy and Pregnancy Register. The UK registry reported the risk of oral cleft as 29 per 1000 (95\% CI, 5-91 per 1000), which is more than 10 times the background risk. ${ }^{22}$ The NAAPR reported that the risk of cleft lip associated with topiramate monotherapy during pregnancy was 14 per 1000 (95\% CI, 5.1-31 per 1000). ${ }^{17}$ The overall MCM rate of topiramate monotherapy has been reported to be 4.2\% (95\% CI, 2.4\%-6.8\%).

Pregabalin use in human pregnancy is relatively less studied. As pregabalin is also used for controlling neuralgic pain, clinical studies on pregabalin may involve confounding factors, such as concomitant medications and co-morbidities, which may be different from those of patients with epilepsy only. This may cause confounding factors in clinical studies, as the concomitant medications and disease spectrum may be different from those of patients with epilepsy only. A multicentre study found that the risk of MCMs associated with pregabalin use in the first trimester of pregnancy was $6.0 \%$, compared with an unexposed risk of $2.1 \%(\mathrm{OR}=3.0$; $95 \% \mathrm{CI}$, $1.2 \%-7.9 \%){ }^{45}$ However, another larger study did not find any significant association between pregabalin use in the first trimester and MCMs. The exposed risk was $5.9 \%$, compared with an unexposed risk of $3.3 \%(\mathrm{OR}=1.78 ; 95 \% \mathrm{CI}, 1.26 \%-2.58 \%)$ and the adjusted OR was 1.16 (95\% CI, 0.81-1.67) according to that study. ${ }^{43}$

Oxcarbazepine is similar to carbamazepine in terms of chemical structure. The NAAPR reported that oxcarbazepine use in pregnancy was associated with a $2.2 \%$ risk of MCMs (95\% CI, 0.6\%-5.5\%). ${ }^{17}$ The EURAP registry data show a 3.0\% MCM risk associated with in-utero oxcarbazepine exposure $(95 \% \mathrm{CI}, 1.4 \%-5.4 \%){ }^{19}$

\section{Pregnancy}

Most women with epilepsy have uneventful pregnancies. ${ }^{2}$ However, they should be informed about their risks of pregnancy complications. For example, the risks of such complications as needing Caesarean section, spontaneous abortion, preeclampsia or pregnancy-induced hypertension, pregnancy-related bleeding complications, fetal growth restriction, and premature uterine contractions, labour, and delivery may be higher than those of women without epilepsy, especially if they are on AEDs. ${ }^{9,46-48}$ Seizure freedom for 9 months to 1 year prior to pregnancy is associated with a high likelihood of seizure freedom during pregnancy. 2,9,49-51 Neither increased seizure frequency nor status epilepticus has been substantially associated with pregnancy. ${ }^{9}$ There is no evidence that focal seizures with or without impairment of consciousness, 
absence, or myoclonic seizures affect pregnancy or the developing fetus adversely unless a fall causes injury or other serious complications. Generalised tonic-clonic seizures may carry a relatively higher risk to the fetus, although their absolute risk level remains very low, and their risk may depend on seizure frequency. ${ }^{52}$ The majority of women with epilepsy experience no change in seizure frequency during pregnancy, whereas a minority of them experience either an increase or a decrease in attack frequency. ${ }^{14,53}$ The increase in seizure frequency may be caused by a pregnancy-induced drop in AED concentration, sleep deprivation, or lack of drug adherence. Women who contemplate going without AEDs during pregnancy should undergo discussions about the potential risk of inadvertent status epilepticus or sudden unexpected death in epilepsy. ${ }^{9,52}$ A balanced discussion may be held with the patient to facilitate informed decision making and provide access to various options. Early and serial fetal ultrasound scans should be offered to pregnant women who are taking AEDs to screen for fetal structural anomalies. ${ }^{2,54}$ Additional screening or diagnostic tests, such as maternal serum tests and fetal echocardiography, should proceed according to clinical indications. ${ }^{2,55}$ Pregnancy in women with epilepsy optimally involves collaborative, multidisciplinary planning and management. The multidisciplinary team should involve specialists, such as obstetricians and neurologists, who have experience providing care for pregnant women with epilepsy. ${ }^{56}$ Monitoring of AED levels during pregnancy may help to guide dosage adjustment. For example, both total and free clearance of lamotrigine may increase substantially during pregnancy, with a peak in the third trimester. ${ }^{57,58} \mathrm{~A}$ decreased lamotrigine level could result in increased seizure frequency. Pregnancy may also affect serum levels of carbamazepine, phenytoin, levetiracetam, and oxcarbazepine to various extents. ${ }^{7,59-61}$ Serum level monitoring may be helpful to inform dosage adjustment during pregnancy. In pregnant women presenting with seizures in the second half of pregnancy that cannot be clearly attributed to epilepsy alone, consideration is usually given to pre-eclampsia, in which case definitive diagnosis should be sought by further assessment. ${ }^{2}$

Fetal complications may occur at slightly higher frequencies in pregnancies of women with epilepsy. A systematic review and meta-analysis that included over 2.8 million pregnancies found that spontaneous miscarriage $(\mathrm{OR}=1.54 ; 95 \% \mathrm{CI}, 1.02-2.32)$, preterm birth before 37 weeks of gestation ( $\mathrm{OR}=1.16$; $95 \% \mathrm{CI}$, 1.01-1.34), and fetal growth restriction $(\mathrm{OR}=1.26$; 95\% CI, 1.20-1.33) were more common in women with epilepsy. ${ }^{48}$ However, the risks of early preterm birth before 34 weeks, gestational diabetes, fetal death or stillbirth, perinatal death, or admission to neonatal intensive care unit did not differ between women with and without epilepsy. In another large US cohort study, the risks of preterm labour $(\mathrm{OR}=1.54 ; 95 \% \mathrm{CI}, 1.50-1.57)$ and stillbirth (adjusted $\mathrm{OR}=1.27 ; 95 \% \mathrm{CI}, 1.17-1.38$ ) were also higher in pregnancies of women with epilepsy. ${ }^{47}$ A 1-minute Apgar score of $<7$ in the neonate may be associated with maternal AED use. ${ }^{12,62}$

\section{Contraception}

The interactions between AEDs and oral contraceptive pills should be discussed with all women with epilepsy of childbearing age. Enzymeinducing AEDs can hinder the effectiveness of oral contraceptives ${ }^{63}$ (Table $2^{64-73}$ ), and women with epilepsy on enzyme-inducing AEDs should avoid combined oral contraceptive pills, combined contraceptive patches, progestogen-only pills, progestogen-only implants, and vaginal ring contraceptives. $^{2,74,75}$ Older-generation AEDs such as phenytoin, carbamazepine, phenobarbital, and primidone may belong to the enzyme-inducing category, but some newer-generation AEDs such as oxcarbazepine also have enzyme-inducing properties. $^{76}$ It may be advisable for women with epilepsy to use other contraceptive methods than the above-mentioned hormone-containing pills and devices because of the risk of contraception failure. If the use of oral contraceptives is unavoidable, hormonal contraception may be adjusted in women taking enzyme-inducing AEDs, although there is little evidence supporting this $\left(\mathrm{Box}^{75,77}\right)$. As different cases are unique, it is advisable to consult specialists who have experience managing these conditions. Copper intrauterine devices, the levonorgestrel-releasing intrauterine system, and medroxyprogesterone acetate injections are less affected by enzymeinducing AEDs. ${ }^{2}$ Some opinions suggest more frequent injections of medroxyprogesterone acetate (every 10 weeks instead of every 12 weeks) in women with epilepsy taking enzyme-inducing AEDs because of potential interactions. ${ }^{64}$ For emergency contraception, a copper intrauterine device should be advised. If the intrauterine device is not suitable or acceptable, a double dose of a total of $3 \mathrm{mg}$ levonorgestrel can be given., ${ }^{2,78,79}$ In contrast, serum lamotrigine levels can be reduced by simultaneous use of any oestrogen-based contraceptive, leading to deteriorated seizure control. ${ }^{2}$ When the concomitant use of the contraceptive is stopped, the lamotrigine dose may need to be adjusted. ${ }^{46}$

\section{Labour}

Spontaneous vaginal delivery is not absolutely contra-indicated in most women with epilepsy. Only about $1 \%$ to $2 \%$ of women with epilepsy develop generalised tonic-clonic seizures during labour. ${ }^{2}$ 
TABLE 2. Common antiepileptic drugs and their main routes of elimination, enzymatic systems involved, and interactions with oral contraceptive pills ${ }^{65}$

\begin{tabular}{|c|c|c|c|}
\hline AED & Main route(s) of elimination & $\begin{array}{l}\text { Main enzymatic system(s) involved in } \\
\text { metabolism }\end{array}$ & Interaction with OCPs \\
\hline Carbamazepine ${ }^{66}$ & Oxidation & $\begin{array}{l}\text { CYP3A4 (active 10,11-epoxide metabolite } \\
\text { cleared by epoxide hydrolase) }\end{array}$ & Significant \\
\hline Lamotrigine $^{67}$ & Glucuronide conjugation & Glucuronyl transferase type 1A4 & Significant \\
\hline Oxcarbazepine ${ }^{64}$ & $\begin{array}{l}\text { Glucuronide conjugation }(>50 \%) \text { and renal excretion } \\
(<30 \%) \text { (refers to the active metabolite MHD) }\end{array}$ & Glucuronyl transferases (refers to MHD) & Significant \\
\hline Phenobarbital 64 & $\begin{array}{l}\text { Oxidation }+\mathrm{N} \text {-glucosidation }(75 \%) \text { and renal } \\
\text { excretion }(25 \%)\end{array}$ & CYP2C9 and CYP2C19 & Significant \\
\hline Phenytoin 64 & Oxidation & CYP2C9 and CYP2C19 & Significant \\
\hline Perampanel $^{68}$ & Oxidation & CYP3A4 & $\begin{array}{l}\text { Significant at higher } \\
\text { dosages }\end{array}$ \\
\hline Topiramate 64,69 & Oxidation (20\%-60\%) and renal excretion & Inducible CYP isoforms (40\%-80\%) & $\begin{array}{l}\text { Significant at higher } \\
\text { dosages (>200 mg per day) }\end{array}$ \\
\hline Ethosuximide 64 & Oxidation & CYP3A4 & Probably insignificant \\
\hline Gabapentin ${ }^{70}$ & Renal excretion & None & Probably insignificant \\
\hline Lacosamide $^{71,72}$ & Demethylation and renal excretion & CYP2C19, CYP2C9, and CYP3A4 & Probably insignificant \\
\hline Levetiracetam $^{73}$ & Renal excretion (75\%) and hydrolysis (25\%) & Hydrolase & Probably insignificant \\
\hline Pregabalin 64 & Renal excretion & None & Probably insignificant \\
\hline
\end{tabular}

Abbreviations: $\mathrm{AED}=$ antiepileptic drug; CYP = cytochrome P450; $\mathrm{MHD}=$ monohydroxycarbazepine; OCPs $=$ oral contraceptive pills

BOX. Possible measures for women taking enzyme-inducing antiepileptic drugs if oral hormonal contraceptives need to be used ${ }^{75,77}$

\footnotetext{
If combined oral contraceptives cannot be avoided, consider:

- at least $50 \mu \mathrm{g}$ oestrogen dose

- tricycling (taking three packets back-to-back without a pill-free interval)

- reducing the pill-free interval to 4 days

If breakthrough bleeding occurs while using combined hormonal contraceptives,

consider:

- increasing the dose of oral ethinylestradiol to $70 \mu \mathrm{g}$ on specialist advice
}

The EURAP registry reported seizure occurrence in $3.5 \%$ of women with epilepsy in labour. ${ }^{80}$ An epilepsy diagnosis per se is not an indication for elective Caesarean section or labour induction. ${ }^{2}$ Antiepileptic drugs should be continued orally or intravenously. Measures such as adequate analgesia, including transcutaneous electrical nerve stimulation, nitrous oxide and oxygen, and regional analgesia, are recommended to reduce pain and emotional distress, but they may trigger seizures. ${ }^{2}$ Pethidine, also known as meperidine, should be used with caution for analgesia during labour in women with epilepsy. Its metabolites may reduce the seizure threshold.$^{81}$ Caesarean section may be necessary if seizures are frequent or prolonged. ${ }^{2}$ Seizures during labour should be terminated as quickly as possible to avoid maternal and fetal complications. Benzodiazepines are the drugs of choice, ${ }^{2}$ and phenytoin can also be given intravenously. ${ }^{82}$ Magnesium sulphate is a treatment option if a diagnosis of eclampsia is made. ${ }^{2}$
Some clinicians may prescribe vitamin $\mathrm{K}$ to women with epilepsy on enzyme-inducing AEDs in the last month of pregnancy to prevent haemorrhagic disease in the newborn. The usual dose is about 10 to $20 \mathrm{mg} /$ day of oral vitamin $\mathrm{K}$. There are insufficient data to fully support or refute maternal vitamin $\mathrm{K}$ prophylaxis. $^{2,7,83}$ It has been recommended that newborns of women with epilepsy be given $1 \mathrm{mg}$ of vitamin K1 parenterally at delivery. ${ }^{2}$

\section{Breastfeeding}

There is no absolute contra-indication to breastfeeding by women with epilepsy who are taking AEDs. ${ }^{2,84}$ However, mothers who take AEDs should be counselled about the potential risks of breastfeeding. Many AEDs are excreted in breast milk. The amount of drug absorbed by the infant depends on various factors, including the maternal plasma concentration, the degree of drug transfer to breast milk, and the amount of breast milk consumed by the infant. The degree of drug transfer to breast milk is inversely dependent on the drug's protein binding ability ${ }^{76}$ Primidone, levetiracetam, barbiturates, benzodiazepines, lamotrigine, gabapentin, topiramate, ethosuximide, and zonisamide probably have significant penetration into breast milk..$^{7,76,85,86}$ However, there is no evidence to show that indirect AED exposure through breastfeeding has clinically significant effects on offspring. ${ }^{2,87,88}$ The potential risks of breastfeeding should be balanced by the benefits of breastfeeding for both the neonate and the mother. ${ }^{84}$ 
TABLE 3. Summary of epilepsy management issues in women with epilepsy

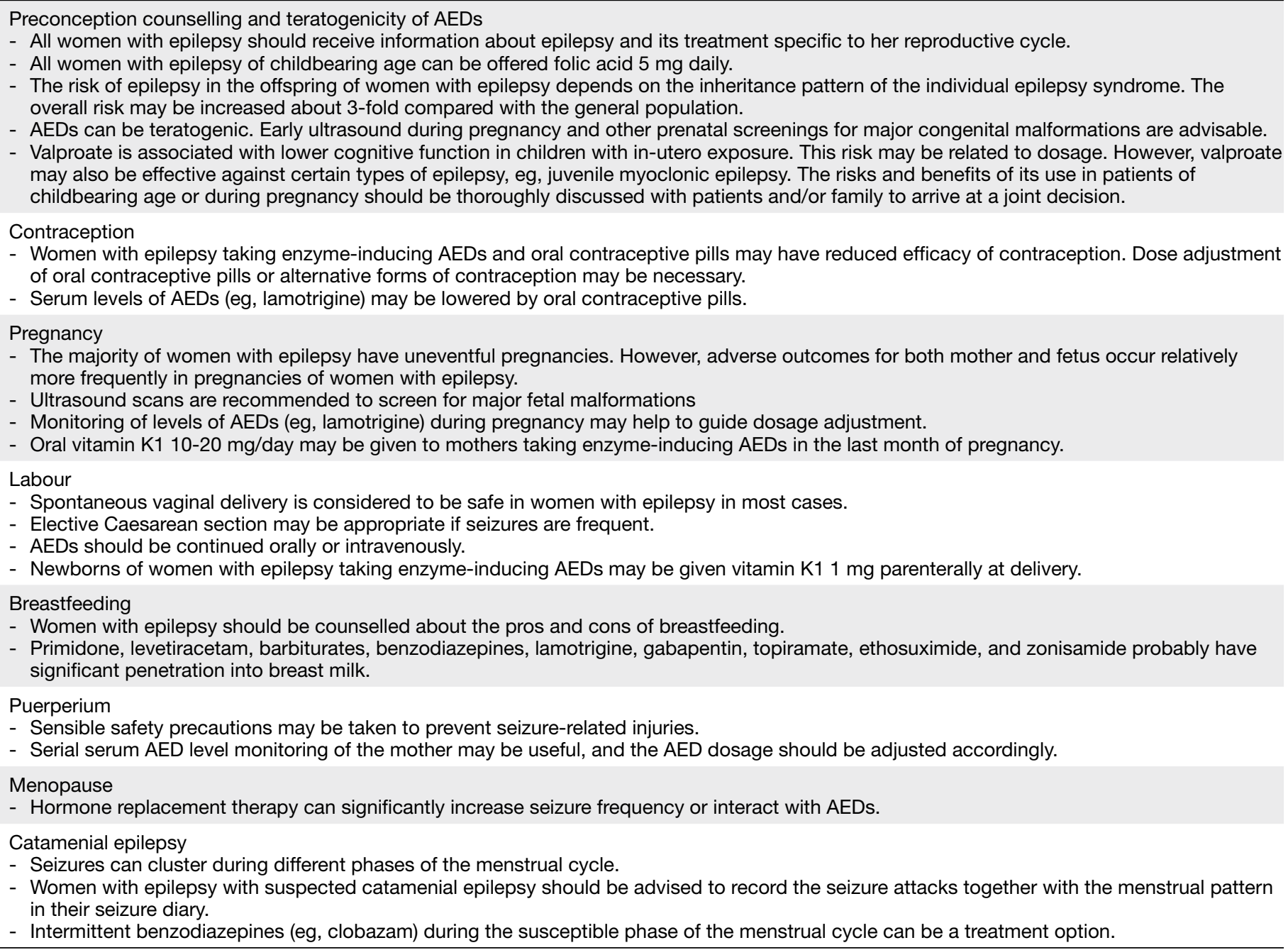

Abbreviation: AED = antiepileptic drug

\section{Puerperium}

Women with epilepsy who have just given birth might face significant anxiety concerning the risk of accidents should they develop breakthrough seizures when they take care of their infants. While there is risk of injury to the infant, reassurance should be provided to the parents, as the actual risk level is probably low. ${ }^{89}$ Safety precautions that are simple to implement could further reduce such risks significantly. ${ }^{2}$ Mothers should breastfeed their babies while sitting on floor cushions to avoid dropping their babies should a seizure occur. If there is an aura, the mother should lay the baby down. ${ }^{2}$ The mother bathing the baby in a bathtub by herself could potentially carry some drowning risk if a seizure occurs. The same risk also applies to the mother carrying the baby single-handedly. ${ }^{46}$ Supervision by the partner or a caregiver may help to prevent injury to the baby should a seizure occur. ${ }^{2}$ Information may also be given to parents early to facilitate preparation or home modification to provide an optimal environment to care for the newborn. Seizure frequency may be exacerbated during the postpartum period for reasons such as lack of sleep and drug non-compliance. ${ }^{90}$ Serial serum AED level monitoring of the mother may be useful, as there may be physiological changes during the puerperal period, especially with certain agents such as lamotrigine. ${ }^{57,91}$ Maintaining the serum drug level at approximately the pre-conception level is advisable, provided that the woman had good seizure control before the pregnancy. ${ }^{51,92}$ Dosages of AEDs should be adjusted accordingly to avoid postpartum toxicity or deteriorated seizure control. ${ }^{2}$

\section{Reproduction technology}

With advancements in the field of reproduction technology, clinicians may receive questions on such technologies from women with epilepsy. Reproductive intervention may have implications 
for women with epilepsy and their offspring. For example, ovarian stimulation with gonadotropin may induce seizure exacerbation in women with epilepsy. ${ }^{93}$ Epilepsy is a heterogeneous disease entity, and although genetics play a part in its aetiology, it can have implications for many bodily functions. Single gene (ie, Mendelian) disorders account for only a small proportion of patients. The implications of these genetic factors in the offspring's life and development are often variable and complicated by many different factors. Reproductive options and application of reproductive technology, such as pre-implantation diagnosis, remain controversial. Whenever possible, cases should be referred to appropriate specialists, including geneticists and obstetricians, for proper counselling.

\section{Menopause}

Hormonal profile changes can affect seizure control in women with epilepsy. ${ }^{94}$ Clinicians should remind patients that hormone replacement therapy can significantly increase seizure frequency during menopause, particularly in women with catamenial epilepsy. ${ }^{95}$ Hormone replacement therapy (which entails the administration of exogenous female sex hormones) and contraceptive pills probably have similar drug interactions with AEDs. ${ }^{96}$

\section{Catamenial epilepsy}

Epileptic seizures may be triggered by serum hormonal changes. Catamenial epilepsy is characterised by an increased seizure frequency during certain phase(s) of the menstrual cycle compared with baseline. However, there is no uniform definition for it. The seizures can cluster in different phases, such as the perimenstrual, periovulatory, and luteal phases of the menstrual cycle. ${ }^{97}$ Recognition of the catamenial seizure pattern can be challenging, as irregular menstrual cycles and anovulatory cycles are common. Women whose seizure occurrence is suspected to be related to the menstrual cycle should be advised to record the seizure attacks together with the phase of the menstrual cycle in their seizure diaries. Prolonged observation may be needed before a catamenial epilepsy pattern is recognised. Treatments include intermittent benzodiazepines (eg, clobazam) during the susceptible phase of the menstrual cycle. ${ }^{98,99}$ Increasing the anticonvulsant dosage during susceptible periods of the menstrual cycle may also be feasible. Hormonal therapy has not yet been proven to be effective in general. ${ }^{100}$ It may be beneficial in women with more frequent seizures around the perimenstrual period, especially in women with regular menstrual cycles. ${ }^{101,102}$ However, further studies are probably needed before routine clinical use can be suggested. ${ }^{100}$ Acetazolamide, used either daily or perimenstrually, may have benefits for catamenial epilepsy, although the evidence to support its use is limited..$^{93,94,103,104}$

\section{Conclusion}

New information has accumulated recently, providing new insight into the care of women with epilepsy and the implications for their offspring (Table 3). Thorough discussions with women with epilepsy may increase patients' levels of comfort and care, especially regarding major treatment decision on the issues of drug teratogenicity, neurobehavioral adverse effects on offspring, pregnancy, breastfeeding, contraception, reproduction technology, menopause, and catamenial epilepsy.

\section{Author contributions}

Concept or design: All authors.

Acquisition of data: RSK Chang.

Analysis and interpretation of data: RSK Chang.

Drafting of the manuscript: RSK Chang, KHK Lui, AWY Yung. Critical revision of the manuscript for important intellectual content: RSK Chang, H Leung.

All authors had full access to the data, contributed to the study, approved the final version for publication and take responsibility for its accuracy and integrity.

\section{Conflicts of interest}

All authors have disclosed no conflicts of interest.

\section{Funding/support}

This project was supported in part by an unrestricted grant from the Hong Kong Epilepsy Society. All authors are members of the Hong Kong Epilepsy Society.

\section{Disclaimer}

This consensus statement is designed to assist clinicians by providing an analytical framework for treatment of women with epilepsy. It is not intended to establish a community standard of care, replace a clinician's medical judgement, or establish a protocol for all patients.

\section{References}

1. Guideline Development Group, Hong Kong Epilepsy Society. The Hong Kong Epilepsy Guideline 2009. Hong Kong Med J 2009;15 Suppl 5:6-28.

2. Royal College of Obstetricians and Gynaecologists. Epilepsy in Pregnancy (Green-top Guideline No. 68). Available from: https://www.rcog.org.uk/en/guidelinesresearch-services/guidelines/gtg68/. Accessed 19 Jul 2020 .

3. Ottman R, Hirose S, Jain S, et al. Genetic testing in the epilepsies-report of the ILAE Genetics Commission. Epilepsia 2010;51:655-70.

4. Peljto AL, Barker-Cummings C, Vasoli VM, et al. Familial risk of epilepsy: a population-based study. Brain 2014;137:795-805.

5. Billings RE. Decreased hepatic 5, 10-methylenetetrahydrofolate reductase activity in mice after chronic phenytoin treatment. Mol Pharmacol 
1984;25:459-66.

6. Kaaja E, Kaaja R, Hiilesmaa V. Major malformations in offspring of women with epilepsy. Neurology 2003;60:5759.

7. Harden CL, Pennell PB, Koppel BS, et al. Management issues for women with epilepsy-focus on pregnancy (an evidence-based review): III. Vitamin K, folic acid, blood levels, and breast-feeding: report of the Quality Standards Subcommittee and Therapeutics and Technology Assessment Subcommittee of the American Academy of Neurology and the American Epilepsy Society. Epilepsia 2009;50:1247-55.

8. Betts T, Fox C. Proactive pre-conception counselling for women with epilepsy-is it effective? Seizure 1999;8:3227.

9. Harden CL, Hopp J, Ting TY, et al. Management issues for women with epilepsy-focus on pregnancy (an evidencebased review): I. Obstetrical complications and change in seizure frequency: report of the Quality Standards Subcommittee and Therapeutics and Technology Assessment Subcommittee of the American Academy of Neurology and the American Epilepsy Society. Epilepsia 2009;50:1229-36.

10. Shorvon SD, Tomson T, Cock HR. The management of epilepsy during pregnancy-progress is painfully slow. Epilepsia 2009;50:973-4.

11. Fried S, Kozer E, Nulman I, Einarson TR, Koren G. Malformation rates in children of women with untreated epilepsy: a meta-analysis. Drug Saf 2004;27:197-202.

12. Harden CL, Meador KJ, Pennell PB, et al. Management issues for women with epilepsy-focus on pregnancy (an evidence-based review): II. Teratogenesis and perinatal outcomes: report of the Quality Standards Subcommittee and Therapeutics and Technology Subcommittee of the American Academy of Neurology and the American Epilepsy Society. Epilepsia 2009;50:1237-46.

13. Morrow J, Russell A, Guthrie E, et al. Malformation risks of antiepileptic drugs in pregnancy: a prospective study from the UK Epilepsy and Pregnancy Register. J Neurol Neurosurg Psychiatry 2006;77:193-8.

14. Meador K, Reynolds MW, Crean S, Fahrbach K, Probst C. Pregnancy outcomes in women with epilepsy: a systematic review and meta-analysis of published pregnancy registries and cohorts. Epilepsy Res 2008;81:1-13.

15. Tomson T, Marson A, Boon P, et al. Valproate in the treatment of epilepsy in girls and women of childbearing potential. Epilepsia 2015;56:1006-19.

16. Holmes LB, Wyszynski DF, Lieberman E. The AED (antiepileptic drug) pregnancy registry: a 6-year experience. Arch Neurol 2004;61:673-8.

17. Hernández-Díaz S, Smith CR, Shen A, et al. Comparative safety of antiepileptic drugs during pregnancy. Neurology 2012;78:1692-9.

18. Reinisch JM, Sanders SA, Mortensen EL, Rubin DB. In utero exposure to phenobarbital and intelligence deficits in adult men. JAMA 1995;274:1518-25.

19. Tomson T, Battino D, Bonizzoni E, et al. Comparative risk of major congenital malformations with eight different antiepileptic drugs: a prospective cohort study of the EURAP registry. Lancet Neurol 2018;17:530-8.

20. Campbell E, Kennedy F, Russell A, et al. Malformation risks of antiepileptic drug monotherapies in pregnancy: updated results from the UK and Ireland Epilepsy and
Pregnancy Registers. J Neurol Neurosurg Psychiatry 2014;85:1029-34.

21. Mawhinney E, Craig J, Morrow J, et al. Levetiracetam in pregnancy: results from the UK and Ireland epilepsy and pregnancy registers. Neurology 2013;80:400-5.

22. Hunt S, Russell A, Smithson WH, et al. Topiramate in pregnancy: preliminary experience from the UK Epilepsy and Pregnancy Register. Neurology 2008;71:272-6.

23. Vanoverloop D, Schnell RR, Harvey EA, Holmes LB. The effects of prenatal exposure to phenytoin and other anticonvulsants on intellectual function at 4 to 8 years of age. Neurotoxicol Teratol 1992;14:329-35.

24. Scolnik D, Nulman I, Rovet J, et al. Neurodevelopment of children exposed in utero to phenytoin and carbamazepine monotherapy. JAMA 1994;271:767-70.

25. Wide K, Henning E, Tomson T, Winbladh B. Psychomotor development in preschool children exposed to antiepileptic drugs in utero. Acta Paediatr 2002;91:40914.

26. Arpino C, Brescianini S, Robert E, et al. Teratogenic effects of antiepileptic drugs: use of an International Database on Malformations and Drug Exposure (MADRE). Epilepsia 2000;41:1436-43.

27. Bertollini R, Mastroiacovo P, Segni G. Maternal epilepsy and birth defects: a case-control study in the Italian Multicentric Registry of Birth Defects (IPIMC). Eur J Epidemiol 1985;1:67-72.

28. Artama M, Auvinen A, Raudaskoski T, Isojärvi I, Isojärvi J. Antiepileptic drug use of women with epilepsy and congenital malformations in offspring. Neurology 2005;64:1874-8.

29. Samrén EB, van Duijn CM, Christiaens GC, Hofman A, Lindhout D. Antiepileptic drug regimens and major congenital abnormalities in the offspring. Ann Neurol 1999;46:739-46.

30. Jentink J, Loane MA, Dolk $\mathrm{H}$, et al. Valproic acid monotherapy in pregnancy and major congenital malformations. N Engl J Med 2010;362:2185-93.

31. Meador KJ, Baker GA, Browning N, et al. Cognitive function at 3 years of age after fetal exposure to antiepileptic drugs. N Engl J Med 2009;360:1597-605.

32. Meador KJ, Baker GA, Browning N, et al. Fetal antiepileptic drug exposure and cognitive outcomes at age 6 years (NEAD study): a prospective observational study. Lancet Neurol 2013;12:244-52.

33. Meador KJ, Baker GA, Browning N, et al. Effects of fetal antiepileptic drug exposure: outcomes at age 4.5 years. Neurology 2012;78:1207-14.

34. Gaily E, Kantola-Sorsa E, Hiilesmaa V, et al. Normal intelligence in children with prenatal exposure to carbamazepine. Neurology 2004;62:28-32.

35. Bromley R, Weston J, Adab N, et al. Treatment for epilepsy in pregnancy: neurodevelopmental outcomes in the child. Cochrane Database Syst Rev 2014;(10):CD010236.

36. Adab N, Jacoby A, Smith D, Chadwick D. Additional educational needs in children born to mothers with epilepsy. J Neurol Neurosurg Psychiatry 2001;70:15-21.

37. Adab N, Kini U, Vinten J, et al. The longer term outcome of children born to mothers with epilepsy. J Neurol Neurosurg Psychiatry 2004;75:1575-83.

38. Bromley RL, Mawer GE, Briggs M, et al. The prevalence of neurodevelopmental disorders in children prenatally exposed to antiepileptic drugs. J Neurol Neurosurg 
Psychiatry 2013;84:637-43.

39. Christensen J, Grønborg TK, Sørensen MJ, et al. Prenatal valproate exposure and risk of autism spectrum disorders and childhood autism. JAMA 2013;309:1696-703.

40. Harden CL, Meador KJ, Pennell PB, et al. Practice parameter update: management issues for women with epilepsy-focus on pregnancy (an evidence-based review): teratogenesis and perinatal outcomes: report of the Quality Standards Subcommittee and Therapeutics and Technology Assessment Subcommittee of the American Academy of Neurology and American Epilepsy Society. Neurology 2009;73:133-41.

41. Jentink J, Dolk H, Loane MA, et al. Intrauterine exposure to carbamazepine and specific congenital malformations: systematic review and case-control study. BM] 2010;341:c6581.

42. Tomson T, Battino D, Bonizzoni E, et al. Dose-dependent risk of malformations with antiepileptic drugs: an analysis of data from the EURAP epilepsy and pregnancy registry. Lancet Neurol 2011;10:609-17.

43. Patorno E, Bateman BT, Huybrechts KF, et al. Pregabalin use early in pregnancy and the risk of major congenital malformations. Neurology 2017;88:2020-5.

44. Holmes LB, Mittendorf R, Shen A, Smith CR, HernandezDiaz S. Fetal effects of anticonvulsant polytherapies: different risks from different drug combinations. Arch Neurol 2011;68:1275-81.

45. Winterfeld U, Merlob P, Baud D, et al. Pregnancy outcome following maternal exposure to pregabalin may call for concern. Neurology 2016;86:2251-7.

46. Datta S, Muñoz-Largacha JA, Li L, Zhao GQ, Litle VR. Subcutaneous metastases from early stage esophageal adenocarcinoma case report. Int J Surg Case Rep 2016;29:108-12.

47. MacDonald SC, Bateman BT, McElrath TF, HernándezDiáz S. Mortality and morbidity during delivery hospitalization among pregnant women with epilepsy in the United States. JAMA Neurol 2015;72:981-8.

48. Viale L, Allotey J, Cheong-See F, et al. Epilepsy in pregnancy and reproductive outcomes: a systematic review and meta-analysis. Lancet 2015;386:1845-52.

49. Vajda FJ, Hitchcock A, Graham J, O’Brien T, Lander C, Eadie M. Seizure control in antiepileptic drug-treated pregnancy. Epilepsia 2008;49:172-6.

50. Gjerde IO, Strandjord RE, Ulstein M. The course of epilepsy during pregnancy: a study of 78 cases. Acta Neurol Scand 1988;78:198-205.

51. Harden CL, Hopp J, Ting TY, et al. Practice parameter update: management issues for women with epilepsyfocus on pregnancy (an evidence-based review): obstetrical complications and change in seizure frequency: report of the Quality Standards Subcommittee and Therapeutics and Technology Assessment Subcommittee of the American Academy of Neurology and American Epilepsy Society. Neurology 2009;73:126-32.

52. Pennell PB. Antiepileptic drugs during pregnancy: what is known and which AEDs seem to be safest? Epilepsia 2008;49 Suppl 9:43-55.

53. European Registry of Antiepileptic Drugs in Pregnancy (EURAP). Seizure control and treatment in pregnancy: observations from the EURAP epilepsy pregnancy registry. Neurology. 2006;66:354-60.

54. National Institute for Health and Care Excellence, UK
Government. Epilepsies: diagnosis and management. Clinical guideline [CG137]. 2013. Available from: https://www.nice.org.uk/guidance/cg137/chapter/1Guidance\#women-and-girls-with-epilepsy. Accessed 19 Jul 2020.

55. International Society of Ultrasound in Obstetrics and Gynecology, Carvalho JS, et al. ISUOG Practice Guidelines (updated): sonographic screening examination of the fetal heart. Ultrasound Obstet Gynecol 2013;41:348-59.

56. Bhatia M, Adcock JE, Mackillop L. The management of pregnant women with epilepsy: a multidisciplinary collaborative approach to care. The Obstet Gynaecol 2017;19:279-88.

57. de Haan GJ, Edelbroek P, Segers J, et al. Gestation-induced changes in lamotrigine pharmacokinetics: a monotherapy study. Neurology 2004;63:571-3.

58. Pennell PB, Peng L, Newport DJ, et al. Lamotrigine in pregnancy: clearance, therapeutic drug monitoring, and seizure frequency. Neurology 2008;70:2130-6.

59. Pennell PB. Antiepileptic drug pharmacokinetics during pregnancy and lactation. Neurology 2003;61:S35-42.

60. Westin AA, Nakken KO, Johannessen SI, Reimers A, Lillestølen KM, Brodtkorb E. Serum concentration/ dose ratio of topiramate during pregnancy. Epilepsia 2009;50:480-5.

61. Reisinger TL, Newman M, Loring DW, Pennell PB, Meador KJ. Antiepileptic drug clearance and seizure frequency during pregnancy in women with epilepsy. Epilepsy Behav 2013;29:13-8.

62. Viinikainen K, Heinonen S, Eriksson K, Kälviäinen R. Community-based, prospective, controlled study of obstetric and neonatal outcome of 179 pregnancies in women with epilepsy. Epilepsia 2006;47:186-92.

63. World Health Organization. Epilepsy: a manual for physicians. 2004. Available from: https://apps.who.int/ iris/bitstream/handle/10665/205014/B0769.pdf Accessed 19 Jul 2020.

64. Reddy DS. Clinical pharmacokinetic interactions between antiepileptic drugs and hormonal contraceptives. Expert Rev Clin Pharmacol 2010;3:183-92.

65. Perucca E. Clinically relevant drug interactions with antiepileptic drugs. Br J Clin Pharmacol 2006;61:246-55.

66. Tolou-Ghamari Z, Zare M, Habibabadi JM, Najafi MR. A quick review of carbamazepine pharmacokinetics in epilepsy from 1953 to 2012. J Res Med Sci 2013;18(Suppl 1):S81-5.

67. Sabers A, Ohman I, Christensen J, Tomson T. Oral contraceptives reduce lamotrigine plasma levels. Neurology 2003;61:570-1.

68. Patsalos PN. The clinical pharmacology profile of the new antiepileptic drug perampanel: a novel noncompetitive AMPA receptor antagonist. Epilepsia 2015;56:12-27.

69. Rosenfeld WE, Doose DR, Walker SA, Nayak RK. Effect of topiramate on the pharmacokinetics of an oral contraceptive containing norethindrone and ethinyl estradiol in patients with epilepsy. Epilepsia 1997;38:31723.

70. Eldon MA, Underwood BA, Randinitis EJ, Sedman AJ. Gabapentin does not interact with a contraceptive regimen of norethindrone acetate and ethinyl estradiol. Neurology 1998;50:1146-8.

71. Cawello W, Rosenkranz B, Schmid B, Wierich W. Pharmacodynamic and pharmacokinetic evaluation of 
coadministration of lacosamide and an oral contraceptive (levonorgestrel plus ethinylestradiol) in healthy female volunteers. Epilepsia 2013;54:530-6.

72. Cawello W. Clinical pharmacokinetic and pharmacodynamic profile of lacosamide. Clin Pharmacokinet 2015;54:90114.

73. Ragueneau-Majlessi I, Levy RH, Janik F. Levetiracetam does not alter the pharmacokinetics of an oral contraceptive in healthy women. Epilepsia 2002;43:697702 .

74. Curtis KM, Tepper NK, Jatlaoui TC, et al. U.S. medical eligibility criteria for contraceptive use, 2016. MMWR Recomm Rep 2016;65:1-103.

75. Gooneratne IK, Wimalaratna M, Ranaweera AK, Wimalaratna S. Contraception advice for women with epilepsy. BMJ 2017;357:j2010.

76. Pennell PB, Gidal BE, Sabers A, Gordon J, Perucca E. Pharmacology of antiepileptic drugs during pregnancy and lactation. Epilepsy Behav 2007;11:263-9.

77. The Faculty of Sexual \& Reproductive Healthcare of the Royal College of Obstetricians \& Gynaecologists. FSRH CEU guidance: drug interactions with hormonal contraception. Available from: https://www.fsrh.org/ standards-and-guidance/documents/ceu-clinicalguidance-drug-interactions-with-hormonal/. Accessed 11 Oct 2018

78. The Faculty of Sexual \& Reproductive Healthcare of the Royal College of Obstetricians \& Gynaecologists. FSRH Guideline Emergency Contraception. Available from: https://www.fsrh.org/standards-and-guidance/ documents/ceu-clinical-guidance-emergencycontraception-march-2017/. Accessed 10 Oct 18.

79. Black KI, Hussainy SY. Emergency contraception: oral and intrauterine options. Aust Fam Physician 2017;46:722-6.

80. Pennell PB. EURAP outcomes for seizure control during pregnancy: useful and encouraging data. Epilepsy Curr 2006;6:186-8

81. Marinella MA. Meperidine-induced generalized seizures with normal renal function. South Med J 1997;90:556-8.

82. ACOG educational bulletin. Seizure disorders in pregnancy. Number 231, December 1996. Committee on Educational Bulletins of the American College of Obstetricians and Gynecologists [editorial]. Int J Gynaecol Obstet 1997;56:279-86.

83. Yamasmit W, Chaithongwongwatthana S, Tolosa JE. Prenatal vitamin K1 administration in epileptic women to prevent neonatal hemorrhage: is it effective? J Reprod Med 2006;51:463-6.

84. Veiby G, Bjørk M, Engelsen BA, Gilhus NE. Epilepsy and recommendations for breastfeeding. Seizure 2015;28:5765.

85. Ohman I, Vitols $S$, Tomson T. Lamotrigine in pregnancy: pharmacokinetics during delivery, in the neonate, and during lactation. Epilepsia 2000;41:709-13.
86. Davanzo R, Dal Bo S, Bua J, Copertino M, Zanelli E, Matarazzo L. Antiepileptic drugs and breastfeeding. Ital J Pediatr 2013;39:50.

87. Meador KJ, Baker GA, Browning N, et al. Effects of breastfeeding in children of women taking antiepileptic drugs. Neurology 2010;75:1954-60.

88. Meador KJ, Baker GA, Browning N, et al. Breastfeeding in children of women taking antiepileptic drugs: cognitive outcomes at age 6 years. JAMA Pediatr 2014;168:729-36.

89. Fox $\mathrm{C}$, Betts $\mathrm{T}$. How much risk does a woman with active epilepsy pose to her newborn child in the puerperium? A pilot study. Seizure 1999;8:367-9.

90. Thomas SV, Syam U, Devi JS. Predictors of seizures during pregnancy in women with epilepsy. Epilepsia 2012;53:e85-8

91. Tran TA, Leppik IE, Blesi K, Sathanandan ST, Remmel R. Lamotrigine clearance during pregnancy. Neurology 2002;59:251-5.

92. Tomson T, Landmark CJ, Battino D. Antiepileptic drug treatment in pregnancy: changes in drug disposition and their clinical implications. Epilepsia 2013;54:405-14.

93. Mostacci B, Esposto R, Lello S, Bisulli F, Licchetta L, Tinuper P. Estrogen-related seizure exacerbation following hormone therapy for assisted reproduction in women with epilepsy. Seizure 2018;61:200-2.

94. Taubøll E, Sveberg L, Svalheim S. Interactions between hormones and epilepsy. Seizure 2015;28:3-11.

95. Harden CL, Pulver MC, Ravdin L, Jacobs AR. The effect of menopause and perimenopause on the course of epilepsy. Epilepsia 1999;40:1402-7.

96. Reimers A. Hormone replacement therapy with estrogens may reduce lamotrigine serum concentrations: a matched case-control study. Epilepsia 2017;58:e6-9.

97. Herzog AG. Catamenial epilepsy: definition, prevalence pathophysiology and treatment. Seizure 2008;17:151-9.

98. Feely M, Gibson J. Intermittent clobazam for catamenial epilepsy: tolerance avoided. J Neurol Neurosurg Psychiatry 1984;47:1279-82.

99. Foldvary-Schaefer N, Falcone T. Catamenial epilepsy: pathophysiology, diagnosis, and management. Neurology 2003;61(6 Suppl 2):S2-15.

100. Herzog AG, Fowler KM, Smithson SD, et al. Progesterone vs placebo therapy for women with epilepsy: a randomized clinical trial. Neurology 2012;78:1959-66.

101. Herzog AG. Catamenial epilepsy: update on prevalence, pathophysiology and treatment from the findings of the NIH Progesterone Treatment Trial. Seizure 2015;28:18-25.

102. Navis A, Harden C. A treatment approach to catamenial epilepsy. Curr Treat Options Neurol 2016;18:30.

103. Reddy DS, Gould J, Gangisetty O. A mouse kindling model of perimenstrual catamenial epilepsy. J Pharmacol Exp Ther 2012;341:784-93.

104. Lim LL, Foldvary N, Mascha E, Lee J. Acetazolamide in women with catamenial epilepsy. Epilepsia 2001;42:746-9. 